\section{Los alcances de la Economía \\ Social y Solidaria \\ en el Norte y en el Sur}

Roberto Casaccia

Integrante de la Organización Retos

al Sur, Uruguay.

Maestrando en Economía Social,

Universidad Nacional de General

Sarmiento, Argentina.
Economía Social y Solidaria /

Perspectivas

RECEPCIÓN: 26/06/15

ACEPTACIÓN FINAL: 28/08/15

\section{Resumen}

El objetivo del siguiente trabajo es describir las características de las concepciones de la Economía Social y Solidaria (ESS) en el Norte -Europa y Estados Unidos- y en el Sur -América Latina-. A partir de los actuales formatos desarrollados en el marco de un incipiente sector económico alternativo, respecto del público y del capitalista, se analizan las tipologías y el potencial instituyente de las nuevas prácticas para la conformación de un nuevo sector socioeconómico y su contribución a la construcción de una alternativa sistémica en cuanto al patrón dominante.

\section{Palabras clave}

- economía solidaria

- economía social

- empresa socia

- Tercer Sector

- enfoque EMES

\section{Resumo}

O objetivo do trabalho seguinte é descrever as características dos conceitos da Economia Social e Solidária (ESS) no Norte -a Europa e os Estados Unidos-e no Sul —América Latina- A partir dos formatos atuais desenvolvidos no contexto de um incipiente setor alternativo, referido ao público e para o capitalista, são analizados os tipos e o potencial instituinte das novas práticas, para a criação de um novo setor socioeconômico e sua contribuição à construção de uma alternativa sistémica respeito ao patrão dominante.

Palavras-chave

- economia solidária

- economia social

- empresa social

- Terceiro Setor

- abordagem EMES
Para citación de este artículo

Casaccia, R. (2015). Los alcances de la Economía Social y Solidaria en el Norte y en el Sur. En Revista $+E$ versión digital, (5), pp. 32-41. Santa Fe, Argentina: Ediciones UNL. 


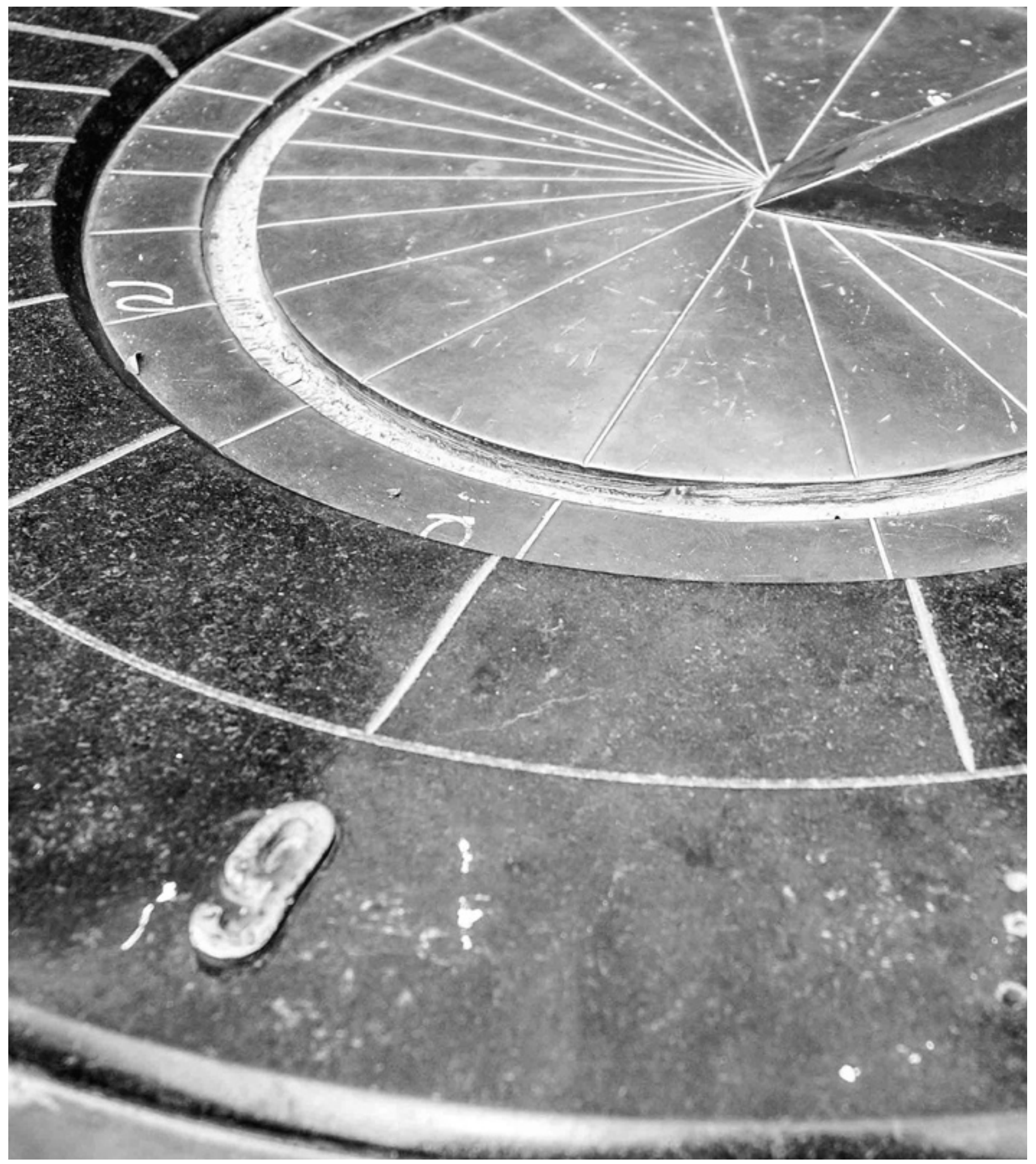




\section{Introducción: economía, desarrollo \\ y la nueva cuestión social}

La dimensión de los problemas socioeconómicos que afectan una franja cada vez mayor de la población mundial representa el campo de análisis fundamental para tratar de entender la crisis económicosocial y poder implementar soluciones viables en el marco de una sociedad fragmentada e inserta en una dinámica global moderna. El sistema capitalista que, a través de la sociedad salarial, tendía a un modelo de inclusión subordinada, limitando la conflictividad social, se ha ido orientando cada vez más hacia la construcción de un modelo dual, que profundiza las desigualdades y agranda las filas de la "clase" de los excluidos.

Las soluciones propuestas en el contexto de la visión neoliberal han supuesto la reducción del papel del Estado como garante de los derechos y otorgado a las dinámicas de mercado el rol de corrector de las ineficiencias del sistema. Pero este modus operandi ha provocado la acentuación de las injusticias y la segregación, agravando la crisis. Las correcciones implementadas han representado mucho más que un simple ajuste de la estructura productiva: han ido generando repercusiones en la organización de la sociedad en su conjunto.

De hecho, la producción de bienes y servicios, a nivel global, se compone de una serie de actividades que no integran ni el sector público ni el sector económico capitalista convencional, configurando un campo heterogéneo de actividades económicas integrado por prácticas diversamente reguladas y reconocidas, cuyos protagonistas principales son los sectores populares acompañados por asociaciones, ONG y la sociedad civil en general. Se trata de actividades económicas basadas en una racionalidad alternativa, que integran diferentes principios (aparentemente contradictorios) definidos, según la latitud en la cual se encuentran, como prácticas de otra economía, popular, social, solidaria o de Tercer Sector. Dicho universo cumple un papel substancial en términos de satisfacción de necesidades y de reproducción de una amplia franja de población en los países del Sur y, hoy en día, cada vez más en los del Norte.

El absolutismo en la dialéctica del sistema económico, además de no tener en cuenta sus propias contradicciones internas, desconoce sistemáticamente la pluralidad de los comportamientos socioeconómicos realmente existentes y subestima la búsqueda de soluciones autónomas (aunque inducida por las condiciones estructurales) de transformación y desarrollo alternativo.

Pero el peso productivo y reproductivo de la otra economía existente, a pesar de limitaciones analíticas y operativas, sigue ocupando a una gran parte de la población económicamente activa. Esta economía se caracteriza por ciertos niveles de articulación con el circuito convencional, como resulta, por ejemplo, del caso de los recuperadores de materiales reciclables en toda América Latina, fuente de insumos y mano de obra barata para la producción de la industria del reciclaje.
En este sentido, se puede decir que las prácticas y los movimientos que proponen la construcción de una ESS surgen como un esfuerzo valioso para intentar responder a los desafíos planteados por la metamorfosis, tan excluyente, de la sociedad posindustrial. Pensar y luchar por alternativas económicas y sociales es particularmente urgente, tanto por el nivel de aceptación, sin precedentes, de la inevitabilidad del capitalismo como opción única, como por el descrédito irreversible de la alternativa sistémica ofrecida por las economías socialistas centralizadas en el último siglo (Sousa Santos, 2002, citado por Gaiger, 2004).

En el contexto actual, es importante tener en cuenta, de acuerdo con Gaiger (2004), que solamente una nueva praxis de inserción en el mundo de la economía y del trabajo puede generar una nueva conciencia y provocar sucesivamente cambios en la práctica. Éste es el requerimiento básico de las experiencias de ESS actualmente existentes, que representan la base potencial para la realización de cambios con alcance sistémico.

El presente trabajo busca sistematizar las propuestas alternativas a las formas de producción capitalistas, centrándose en la clasificación de las mismas en dos grandes grupos sólo a manera de estrategia metodológica, a saber: aquellas prácticas que provienen de los países que denominamos del Norte, es decir, Europa y Estado Unidos, cuyas economías son definidas como las "centrales", versus aquellas que emanan de los países del Sur, especificadamente los de América Latina, cuyas economías son definidas como "periféricas".

\section{Economía Social y Solidaria}

Para poder analizar el fenómeno de la ESS en términos comparativos, entre los países centrales (o del Norte) y los países periféricos (o del Sur) es necesario tener en cuenta tres aspectos fundamentales:

- la dimensión y el desarrollo histórico de las diferentes iniciativas, - el contexto específico de referencia;

- las particularidades y los desafíos de las prácticas en la realidad actual.

Buena parte de las experiencias de ESS de los países que consideramos del centro se encuentra en Europa y Estados Unidos. Por otro lado, en lo que respecta a lo que denominamos el Sur, analizaremos las experiencias que corresponden al subcontinente latinoamericano.

La principal diferencia entre estos contextos está claramente marcada en Latinoamérica por la existencia de pobreza y marginalidad, que ha ido generando el crecimiento de prácticas económicas populares acompañadas a menudo por la acción de la iglesia católica, la resistencia política de los movimientos y el desarrollo de las ciencias sociales. Por lo contrario, en Europa, las propuestas de otra economía 


\section{6 \\ el concepto de ESS en Europa \\ se ha desarrollado para describir \\ a las organizaciones de la denominada \\ "nueva economía social", surgidas \\ en respuesta a la crisis del modelo \\ de desarrollo y a la ruptura \\ del pacto social}

se han enmarcado en la crisis del welfare state y del crecimiento del desempleo, con una consecuente ruptura del pacto social y una tentativa de redistribución de las responsabilidades entre sector público, privado y las iniciativas del sector de la vieja y nueva economía social.

En América Latina, no parece posible promover otra economía sin proponer una postura distinta respecto de la marcada separación entre clases sociales, de la inmensa desigualdad de acceso a servicios básicos y de la exclusión de matriz estructural que ha caracterizado la inserción de la región en la dinámica capitalista global. La exclusión no constituye, como pudo (o puede) ser inicialmente considerada en el Norte, un fenómeno coyuntural, producto del pacto social entrado en crisis, sino que es parte intrínseca del proceso histórico de construcción social y económica de la sociedad.

\subsection{Desde el Norte: Nueva Economía Social y Tercer Sector} El concepto de ESS en Europa se ha desarrollado para describir a las organizaciones de la denominada "nueva economía social" (Laville, 1998), surgidas en respuesta a la crisis del modelo de desarrollo y a la ruptura del pacto social, fundados en la sinergia Estado-mercado, lo que implicaba una repartición y una neta jerarquización de los formatos económicos.

Las nuevas iniciativas, en un intento por responder al aumento del desempleo estructural y del abandono de ciertos sectores por el mercado y el Estado, han ido agrupando una multiplicidad de actores sociales distinta del asociacionismo de la economía social tradicional (básicamente cooperativas y sociedades mutuales), caracterizadas por rasgos claramente más homogéneos.

A partir de los primeros años de los ' 90 , surge en la literatura europea la noción de empresa social como concepto que describe actividades alternativas que, en varios países del viejo continente, intentan paliar los problemas generados por los crecientes niveles de desempleo. Paralelamente, las empresas sociales van articulando iniciativas con organizaciones non profit, ya que muchas de estas empresas se creaban a través de ONG, como forma concreta de incidir a favor de los sectores excluidos mediante formatos de activación económica (Guerra, 2013).

La nueva economía social en Europa abarca una serie de tipologías que incluye, entre otras:

- comercio justo y finanzas éticas;

- grupos de compras solidarias y servicios de proximidad;

- economía sin dinero (autoproducción, sistemas LETS, ${ }^{1}$

intercambio de saberes open source);

- empresa social (cubre un amplio espejo de modalidades tratadas más adelante).

De acuerdo con Laville (2008), estas iniciativas, expresión de colectivos autogestionados y alternativos, son a la vez reapariciones y emergencias de reivindicaciones fundadas en la igualdad cuyo reconocimiento pasa por la capacidad de actuar en la economía. Todas estas experiencias no pueden encontrar lugar en los clásicos estatutos de la economía social tradicional, de la cual se distinguen por sus finalidades más amplias y la participación de múltiples actores involucrados (stakeholders). El objetivo explícito de servicio a la colectividad y la distribución del poder entre stakeholders son las dos características más específicas de las realidades emergentes (Laville, 2008), que enfatizan una componente solidaria y de proyección público-comunitaria de más amplio alcance. Además del mercado y del Estado, es la propia sociedad que, en un contexto cada vez más complejo, reivindica el derecho de avanzar hacia ensayos y propuestas autónomas, en términos de creación y distribución de recursos y riqueza, es decir, del modo de hacer economía, proponiendo la construcción de un nuevo pacto social.

1) Es decir, Local Exchange Trading Systems (www.letslinkuk.net/). 
Esta concepción, propiamente continental, se distancia del término Tercer Sector de tradición anglosajona, que establece una separación absoluta entre asociaciones y cooperativas, cada vez más cuestionadas y que, fundándose en el concepto de filantropía y de non-profit, respalda básicamente las organizaciones sin fines de lucro. ${ }^{2}$

En su desarrollo hacia nuevas formas, esta escuela mantiene una postura concentrada en los beneficios sociales generados por una cualquier actividad económica, más que por el tipo de organización y gestión de las empresas. De hecho, en su análisis de nuevas formas de hacer economía, la escuela made in USA ha mantenido una postura concentrada sobre los beneficios sociales generados por una cualquier actividad económica y considera, por ende, muchas actividades ligadas a corporaciones como empresa social aunque, según Guerra (2013), no respondan al criterio de autonomía, gestión y distribución democrática de los recursos y de los resultados obtenidos. Esta visión supone un marco de valores y principios que se aleja tanto de la perspectiva europea continental como de la visión latinoamericana, que se expone a continuación.

\subsection{La perspectiva latinoamericana: otra economía para otra sociedad}

Las diferentes propuestas identificadas bajo el umbral de otra economía o ESS en América Latina, así definidas a partir de los años '80, nacen y comparten un análisis crítico de la estructura capitalista a través del rescate de elementos como la autogestión y el asociacionismo, como fundamento para otro desarrollo del sector económico a partir de la base popular. ${ }^{3}$

En ese sentido, las propuestas latinoamericanas adquieren características más radicales respecto del contexto europeo a través de un planteo marcadamente (más) político.

La esfera pública, en combinación con el mercado, no ha conformado en ningún momento un mecanismo de armonización y cohesión de la sociedad en su conjunto. La región mantiene una enorme masa de pobres y excluidos, caracterizándose por el más alto índice de desigualdad del mundo. Puesto que es, además, una de las regiones más urbanizadas, de acuerdo con Coraggio (2013), la pobreza urbana se ha ido convirtiendo en un factor estructural, al tiempo que se ha conservado un gran sector informal rural y urbano que alcanza la mitad de la población económicamente activa. En este marco, la propuesta ligada a una ESS no es por lo tanto interpretable en términos de re-construcción de un pacto social entrado en crisis. Es por esto que se remarca que los proyectos y propuestas para otra economía no puedan ser analizados desde un punto de vista estrictamente económico, sino que es necesario conectarlos con un proceso histórico que tiene su fundamento y energía en las luchas llevadas adelante por los movimientos sociales y retroalimentados por las corrientes de pensamiento contrahegemónico. En la perspectiva latinoamericana se observa que el aspecto económico que caracteriza la ESS, entendido como la satisfacción de necesidades materiales, es esencial para la movilización de las iniciativas; pero para que el fenómeno asuma caracterización sociopolítica, es preciso que ese aspecto económico asuma trascendencia, proyectándose en el espacio público.

Estas prácticas, señala Gaiger,

"expresan, así, una inflexión de la economía popular de base doméstica y familiar, o también, en algunos de sus segmentos, una reconversión de la experiencia obrera del trabajo, a través de la socialización de los medios de producción y de la democratización del poder económico" (2004:231).

En ese contexto se ha ido gestando, a partir de diferentes formas de autoorganización socioeconómica, una serie de actividades como: - bancos comunitarios/populares/comunales, con o sin monedas sociales;

- ferias de productores artesanales, orgánicos y familiares;

- redes de consumo y clubes de trueque;

- empresas recuperadas;

- grupos de recuperadores de materiales reciclables;

- prestación de servicios personales solidarios;

- experiencias ligadas al hábitat y a la vivienda popular y comunidades étnicas.

Las mismas, entre otras, representan las tipologías más difusas en toda la región. ${ }^{4}$

El sentido de las palabras social y solidaria no debe entenderse aquí desde una óptica paternalista o filantrópica, sino como un conjunto de valores tales como la cooperación, lo comunitario y la colaboración, entre otros, que subyacen a una diferente concepción de las relaciones económicas y sociales. La solidaridad se convierte así en un factor diferencial, propio de la (nueva) racionalidad económica, que soporta la práctica en términos de resultados materiales y de otros activos intangibles. Los esfuerzos para la mejora de las condiciones materiales se van ligando irremediablemente a procesos de emancipación y reivindicación de derechos de ciudadanía. De hecho, gracias a la articulación con un conjunto creciente de organizaciones de apoyo, las iniciativas y grupos de ESS persiguen instancias de negociación e intercambio, tanto en el ámbito económico como en el político. Es así que, en los últimos años, América Latina ha logrado, según Coraggio (2013), fortalecer de forma continúa los procesos de incorporación de la ESS al imaginario colectivo y a la acción pública.

Luis Razeto se basaba en el análisis de miembros y las iniciativas mencionadas las definidas "organizaciones económi- se auto reconocen como actores de un cas populares". movimiento de ESS. las dos formas de regulación del conjunto de la sociedad.

3) De hecho, una de las primeras caracterizaciones del fenómeno por parte de 


\section{Formatos económicos alternativos}

La empresa, desde un punto de vista amplio, puede definirse, en acuerdo con Guerra (2013), como una unidad integrada de funciones que utiliza una determinada combinación de factores para producir de manera racional bienes y/o servicios.

En las últimas dos décadas ha nacido una pluralidad de formas económicas que se diferencian entre ellas y del modelo empresarial convencional. En el ámbito del heterogéneo universo de la ESS, se han recuperado y difundido formatos propios de cada contexto que, en términos reales, reafirman las diferencias de miradas observables a nivel conceptual.

\subsection{Las cooperativas: una experiencia compartida Norte-Sur}

El formato cooperativo ha representado, históricamente, el intento alternativo más difuso y eficiente en respuesta a la proliferación del modelo capitalista convencional.

La última Declaración de Identidad Cooperativa adoptada por la II Asamblea General de la Alianza Cooperativa Internacional (ACI) celebrada en septiembre de 1995 en la ciudad de Manchester, para conmemorar su centenario, incluye una definición revisada de cooperativa y una reformulación de los principios y valores del cooperativismo. $\mathrm{La} \mathrm{ACl}$, define a la cooperativa como "una asociación autónoma de personas que se han unido voluntariamente para hacer frente a sus necesidades y aspiraciones económicas, sociales y culturales comunes por medio de una empresa de propiedad conjunta y democráticamente controlada". ${ }^{5}$ Los principios, herencia de los Pioneros de Rochdale, hacen hincapié en siete elementos: membresía abierta y voluntaria; control democrático de los miembros; participación económica de sus miembros; autonomía e independencia; educación, entrenamiento e información; cooperación entre cooperativas y compromiso con la comunidad. ${ }^{6}$

Ahora bien, se puede afirmar que con el pasar de los años diversas tipologías de cooperativas que se constituyeron con el ideal de la solidaridad y ayuda mutua actualmente funcionan como empresas volcadas a una economía de mercado, apoyándose en la búsqueda de competitividad y en la disminución de los costos de producción. Evidencias históricas apuntan a la insuficiente trascendencia socioeconómica de estas organizaciones, que no obstante han conseguido institucionalizarse en el escenario social y económico de la sociedad moderna. De hecho, el cooperativismo ha sido utilizado, conforme a Quijano (citado por Coraggio, 2014:147), por corrientes políticas reformistas con el objetivo de moderar la explotación del trabajador en el marco del sistema capitalista y relegándolo así a un papel subordinado.
Para una ESS que tenga como horizonte una economía del (otro) trabajo, siguiendo a Coraggio (2009), el tema central no puede ser la recuperación del pleno empleo bajo la óptica de un régimen salarial, sino el de reconocer e institucionalizar "otras formas de vida activa", garantizar la reproducción de la vida cotidiana e incluir la experiencia del trabajo.

En este sentido, el formato cooperativo, entendido en un sentido genuino de su práctica, mantiene un papel potencialmente activo y transformador, sobre todo con relación a fenómenos como la recuperación de empresas por mano de los propios trabajadores, especialmente en Latinoamérica, o en algunas experiencias de las cooperativas sociales del contexto europeo.

Las experiencias de autogestión no son (y quizás nunca podrán serlo) un formato empresarial acabado, en cuanto están caracterizadas por un proceso dinámico, dependiente de la interacción del grupo humano que lo lleva adelante, de la tipología de actividad y del entorno socioeconómico en el cual se insertan. Romper con la costumbre de la dependencia y la inserción en el mercado a cualquier precio, elementos cardinales de la sociedad salarial, es quizás el desafío más profundo, ya que la propia sociedad está impregnada y moldeada por estos valores.

La ESS se compone de un conjunto de experiencias que sin duda comparten rasgos constitutivos del cooperativismo y del mutualismo, resaltados por elementos como la solidaridad, la cooperación y la autogestión. La relación entre el movimiento cooperativo tradicional y la ESS está atravesada por una serie de tensiones y es complicado elaborar un diagnóstico sobre las posibilidades de articulación entre ellos. Sin embargo, el formato cooperativo constituye, más allá de las degeneraciones comprobables empíricamente, una realidad que comparte y reafirma el sentido de las iniciativas que reivindican otras formas de hacer economía.

\subsection{Desde el Norte: el enfoque Emergence des Entreprises Sociales en Europe (EMES) y las empresas sociales}

El concepto de "empresa social" aparece por primera vez en el debate del Tercer Sector a principios de la década del '90. Por el lado europeo, se identifica a partir de la novedosa legislación italiana del año 1991, que permite desarrollar actividades económicas a nuevas organizaciones denominadas "cooperativas sociales". En el contexto estadounidense, las ideas de "empresa social" y "emprendimiento social" surgen también en la década del ' 90 , más precisamente en 1993, cuando la Harvard Business School lanza la "Iniciativa de Empresa Social".

Desde entonces se han establecido varias redes internacionales de investigación en la materia, destacándose entre ellas la Red 


\section{6}

La relación entre el movimiento cooperativo tradicional y la ESS está atravesada por una serie de tensiones y es complicado elaborar un diagnóstico sobre las posibilidades de articulación entre ellos

Europea de Investigación, EMES, que reúne y nuclea desde 1996 a la mayoría de los países de la Unión Europea y la Social Enterprise Knowledge Network (SEKN). ${ }^{7}$

En 2011, la Comisión Europea señalaba que la empresa social "es un operador de la economía social, cuyo principal objetivo es tener un impacto social en lugar de obtener un beneficio para sus propietarios o accionistas. Funciona proporcionando bienes y servicios para el mercado de forma emprendedora $\mathrm{e}$ innovadora, utilizando sus beneficios para conseguir objetivos sociales. Está gestionada de forma abierta y responsable y, especialmente, implica a empleados, consumidores y partes interesadas, afectadas por sus actividades comerciales" (Defourny y Nyssens, 2012:24).

Por otra parte, la SEKN, considera empresa social a cualquier tipo de organización o proyecto comprometido en actividades de valor social significativo, o en la producción de bienes y servicios con un propósito social integrado, cualquiera que sea su forma legal. ${ }^{8}$ Siguiendo a Defourny y Nyssens (2012), desde principios de los '80 en Estados Unidos se han utilizado diversos conceptos para describir los comportamientos emprendedores con objetivos sociales, sintetizables en dos grandes escuelas: "generación de ingresos" e "innovación social". La primera se basa en la utilización de estrategias comerciales para emprender negocios que generen ingresos en apoyo de la misión social de una organización sin fines de lucro, como método para ampliar las fuentes de financiamiento. La escuela de la "innovación social" pone énfasis en el comportamiento de los emprendedores, en la calidad de los servicios, en los métodos de producción, en las formas innovadoras de organización, en nuevos mercados, etc. ${ }^{9} \mathrm{Si}$ bien estas escuelas tienen diferencias entre sí, es cada vez más común que se fomenten la generación de ingresos y la innovación social en forma conjunta. En síntesis, la perspectiva estadounidense y anglosajona reconoce como economía social formatos económicos convencionales que deciden orientar su actividad según una visión que contemple algún tipo de objetivo social.

Desde la óptica europea de la EMES, Borzaga, en 2013 (citado por Guerra, 2014:23), resalta cuatro elementos diferenciales de la empresa social con respecto a la economía social tradicional: - objetivo: no se enfoca en los intereses del socio, sino el impacto positivo en la comunidad;

- propiedad: abierta a una multiplicidad de actores, como los voluntarios;

- rubro: hace referencia a ámbitos con elevado valor social;

- distribución de beneficios: no se prevé redistribución entre socios.
7) Fundada en 2001 en colaboración con la Harvard Business School, esta red nuclea a escuelas de negocios líderes en diez países de lberoamérica, dedicándose a la investigación colectiva de carácter hemisférico sobre emprendimientos sociales, Responsabilidad Social Empresarial (RSE) y negocios inclusivos (www. sekn.org/cms).
8) Se puede agregar que distingue entre dos emprendimientos sociales: empresas sociales y organizaciones de la sociedad civil (generadoras de ingresos pero no necesariamente rela- cionados con su misión social) 9) El emprendimiento no es sólo una cuestión de ingresos, sino también de resultados. 
Esta concepción, propiamente continental, se distancia por lo tanto de la perspectiva anglosajona de la SEKN; de hecho, tomando en cuenta el análisis EMES y su tipo ideal de "empresa social", podemos diferenciar entre los enfoques de Europa y Estados Unidos en las distintas dimensiones: económica, social y estructura de gobierno. En síntesis, podría sostenerse que las escuelas norteamericana y anglosajona se basan mayormente en el aspecto estrictamente económico, mientras que la visión europea se centra más en la estructura de gobierno - -tipo de organización y gestión asociativa de los emprendimientos-. Por lo tanto, siguiendo a Guerra (2013), es factible afirmar que la práctica europea tiene más puntos de contacto que diferencias con relación a las elaboraciones de la ESS, propia del contexto latinoamericano.

\subsection{Desde el Sur: los emprendimientos económicos solidarios} Los Emprendimientos Económicos Solidarios (EES) abarcan diversas modalidades de organización económica originadas en la libre asociación de los trabajadores, con base en principios de autogestión, cooperación, eficiencia y viabilidad (Gaiger, 2004). Las prácticas de los EES se inscriben en una racionalidad productiva diferente de la de las empresas de capital; la finalidad básica no es la de maximizar el lucro sino garantizar (cuali y cuantitativamente) la satisfacción de las necesidades, volcada a la mejora y reproducción ampliada de las condiciones de vida. Estas características, según Gaiger (2004), les dan un nivel distinto de las modalidades predominantes de economía popular, donde están en juego necesidades inmediatas de supervivencia o, en términos de Coraggio, de reproducción simple de la vida.

En acuerdo con varios autores, se pueden identificar cuatro principios que describen las experiencias de los EES:

- la pluralidad de principios económicos sobre el cual se basa el emprendimiento;

- la autonomía de la gestión (más allá del apoyo técnico y/o financiero); - el proceso de toma de decisiones, según principios democráticos; - la sociabilidad, entendida como combinación de la relación social con la práctica económica.

Conforme a Gaiger (2004), desde el punto de vista de los beneficios económicos y extra económicos provistos a sus miembros, la eficiencia de las iniciativas de las organizaciones de la ESS descansa en su racionalidad específica, determinada por la apropiación colectiva de los medios de producción, por la autogestión y por el trabajo asociado. El trabajo asociado y autogestionado se vuelve una fuerza productiva peculiar y decisiva por la cual, según Martí (2005), el desafío organizativo de conciliar las decisiones operativas con las estratégicas, así como la eficiencia administrativa con la democracia cooperativa, asumen un papel discriminante en términos de emancipación y legitimación de estas experiencias frente a la sociedad en su conjunto.
En estos términos, la eficiencia y la sustentabilidad se expresan (o tienden a expresarse) en la búsqueda de la combinación ideal para garantizar la producción y reproducción de la vida de la organización y de sus miembros, además de mantener un fuerte arraigo con su propio entorno.

Por otro lado, en las condiciones actuales, la comparación regional (como la internacional) relativiza la elección de un particular estatuto, de matriz cooperativa o asociativa y el recurso a los formatos más recientes que los completan (Laville, 2008).

El rescate y afirmación de valores pueden ser considerados como los principales elementos que contribuyen a constituir la identidad de las organizaciones de la ESS. Siguiendo a Guerra (2013), se puede afirmar que los principios y los valores que guían a los emprendimientos económicos solidarios son, en la medida en que se cumplan, sus principales características distintivas, con independencia de las formas (sociales, jurídicas y organizacionales) adoptadas según el contexto de pertenencia.

En este sentido, França resalta que "las iniciativas se caracterizan por la búsqueda de un equilibrio, que hace referencia a la combinación de los principios económicos (mercantil, de redistribución y de reciprocidad) en relación dinámica entre ellos" (2004:167).

A través de esta combinación se va introduciendo el elemento ético en el ámbito económico y político que, conforme a Gaiger (2004), pasa a incidir con principios normativos irreductibles a la lógica instrumental y utilitaria.

\section{Alcance y potencial sistémico: ¿otro sistema económico o sector de emprendimientos solidarios?}

La creación de iniciativas socioeconómicas alternativas, más allá del peso cuantitativo con relación a las prácticas hegemónicas institucionalizadas, tiene que ser evaluada en términos de su potencial de transformación, bajo una racionalidad que, cualitativamente, ponga en discusión la unilateralidad del patrón de desarrollo. En este sentido, las propuestas de ESS pueden ofrecer una contribución a los procesos de transformación del complejo sistémico en el marco de una economía mixta, integrada, de acuerdo con Coraggio (2009), por la economía del capital, la economía pública y el heterogéneo universo de la economía popular. Ahora bien, esta concepción puede ser leída también en términos de sectores de una economía plural, en la cual el sector social y solidario se compone, según Guerra (2013), de una serie de experiencias y recursos híbridos, donde se combinan la pluralidad de principios económicos con componentes éticos de la vida asociativa que confluyen en acciones en el espacio público. La relación con los sectores preponderantes no plantea la anulación del papel del Estado ni la disolución del mercado, sino una construcción que supone instancias de participación en las decisiones políticas y económicas: el cuadro de referencia podría 
sintetizarse, en ambos contextos geográficos, en la reflexión sobre la relación democracia-economía.

Varias reflexiones teóricas, tanto desde el Norte como desde el Sur, confirman la proliferación de formas económicas alternativas, propias de una realidad posindustrial en la cual se estaría incrementando una gama de modos de producción no capitalistas (Sousa Santos, 2011) o poscapitalista, con un potencial de desarrollo para la definición de otras formas de conciliar economía y sociedad. El resurgimiento de prácticas económicas asociativas, en la última década, responde a contextos muy diversos; por eso sus virtudes no están determinadas a priori sino que constituyen tendencias y posibilidades dependientes, conforme a Gaiger (2004), de las condiciones objetivas y subjetivas en las que cada experiencia se va desarrollando.

En línea general, la reducción de las modalidades convencionales de subsistencia, tanto debido a la incapacidad de absorción del mercado de trabajo como a la ineficacia de las políticas públicas destinadas a compensar momentáneamente dicha insuficiencia (Gaiger, 2004), abren el camino para la constitución de un sector alternativo, organizado e independiente. Esto no significa que las empresas capitalistas estén en vías de extinción y con ellas los mecanismos del complejo sistémico.

Sin embargo, con un punto de vista emancipatorio, la tarea de la ESS puede ser analizada desde una triple perspectiva: económica, social y política, en el marco de una constante tensión teóricopráctica interna al sector de la ESS y, a nivel relacional, con los otros sectores de la economía.

En términos de autonomía, la relación y el papel del Estado, por lo menos en una primera fase, debería desarrollarse en dos ámbitos fundamentales: las políticas públicas (de corte multidimensional) para el fomento, crecimiento y espacio de participación del sector; el marco legal: creación de herramientas que otorguen legitimidad a otros formatos económicos. ${ }^{10}$

El Estado puede y debe reforzar dichos valores a través de la regulación y la promoción de la iniciativa asociativa, pero sin substituir ni intentar cooptar el papel histórico que han de jugar las fuerzas sociales en la transformación del complejo sistémico. En términos de Singer, se trata de avanzar hacia

"una conciliación (...) por medio de negociaciones en que ni los representantes de la sociedad civil ni los del Estado pueden perder su autonomía. Pues de su autonomía depende su autenticidad y de ésta su capacidad de representación, por lo tanto su poder político" (2009:61). ${ }^{11}$

10) Se considera que los valores promovidos en las experiencias de ESS, aunque con diferentes énfasis sobre asociacionismo y proyección política, son expresión de la capacidad creativa en el seno de la sociedad.
11) En este sentido la continua ampliación del espacio de participación directa de los sectores de la sociedad civil en el funcionamiento del Estado representa un gran desafío, para que, siguiendo a Singer (2009), la asignación
Por otra parte, existe una conexión entre la propuesta de la ESS y la apropiación del concepto y del espacio de mercado; de hecho, aunque privilegiando el intercambio entre emprendimientos solidarios, se desarrollan continuamente relaciones con otros sectores del sistema económico. Cualquier propuesta de otra economía no puede tratar de funcionar sin mercado porque esto significaría limitar el objetivo de generar otra forma de hacer economía. Este camino no puede por lo tanto permitirse de rechazar al mercado, sino que debe mantener una perspectiva dinámica, que persiga la producción y reproducción social de este espacio. ${ }^{12}$ Se trata, siguiendo a Singer (2009), de desencadenar un proceso de democratización de la economía substituyendo la competencia por la cooperación, al tiempo que se procura expandir mecanismos políticos de participación.

\section{Consideraciones finales}

La crisis y sus respuestas han promovido el surgimiento de nuevos formatos económicos, todos ellos con un fuerte componente ético social (Guerra, 2014). Existe al respecto una multiplicidad de casos, tanto desde lo que hemos considerado el Norte como desde lo que hemos definido como el Sur. Las diferencias radican sobre todo en el factor organizador, los actores involucrados, los destinos de las utilidades y el modelo de gestión política de los emprendimientos.

\section{Diagrama 1}

Sectores de la Economía Plural

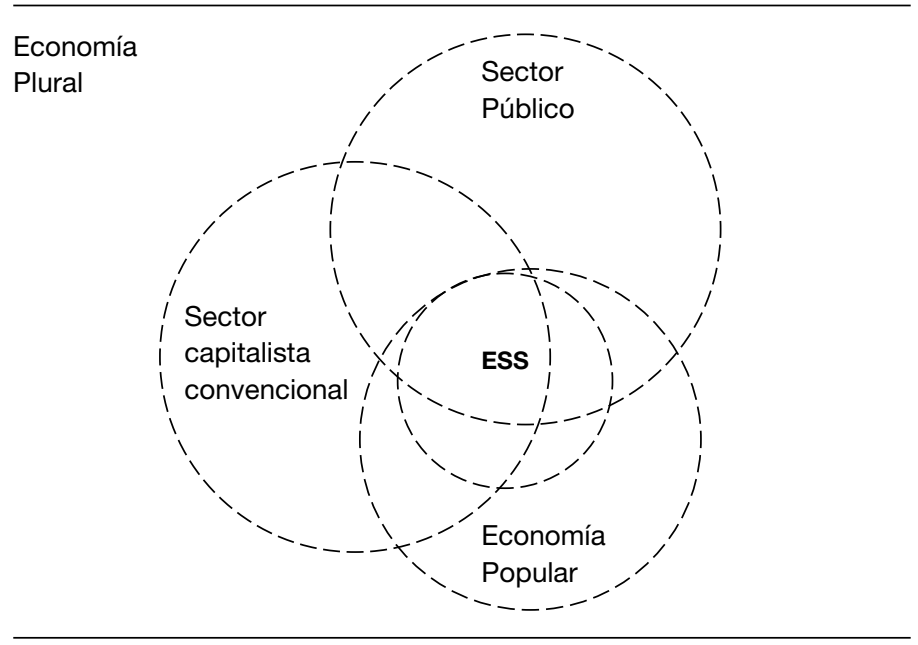

Fuente: elaboración propia sobre la base de Coraggio (2013). de los recursos públicos corresponda lo mejor posible a las necesidades legítimas de cada sector. Lo que implica el avance de la participación de la sociedad civil en el diseño, aprobación y ejecución de políticas públicas.
12) Para configurar estos nuevos equilibrios es preciso, en términos de a Polanyi, re-encastrar la economía en la sociedad, lo que implica, por ende, una adecuada reinstitucionalización del espacio de mercado. 
En este sentido, podemos sugerir que, a pesar de mantener matices distintos, las experiencias europeas y las latinoamericanas comparten la creencia en el potencial subyacente al fortalecimiento de un sector de ESS, sumado al apoyo de políticas públicas que —más allá de la importancia cuantitativa actual— se expresa en su potencial transformador, poniendo en discusión la unilateralidad del proceso de crecimiento como única vía para lograr el desarrollo y el bienestar de la sociedad.

De acuerdo con Oxoby (2010), mientras que en el ámbito europeo se busca mayormente una sinergia entre los diferentes sectores económicos a través de un esfuerzo de armonización intra y extra sectorial, en el contexto latinoamericano el alcance de la propuesta social y solidaria resulta más amplio al debatirse un cambio más grande, a nivel de los diferentes segmentos sociales.

Sin embargo, una variedad cada vez mayor de experiencias locales, comunitarias, de proximidad, de recuperación de empresas y espacios públicos, pasando por nuevas modalidades de distribución y consumo llevadas a cabo por diferentes actores, siguen aisladas entre ellas y pierden así capacidad de incidir mayormente en el conjunto del sistema.

La búsqueda de soluciones para el fortalecimiento de estas experiencias va identificada en la elaboración de un proceso

\section{Referencias bibliográficas}

Coraggio, J.L. (2013). La presencia de la Economía Social y Solidaria (ESS) y su Institucionalización en América Latina, preparado para los Estados Generales de la Economía Social y Solidaria. 17-11 de junio, París.

Coraggio, J.L. (org.) (2014). La economía social desde la periferia. Buenos Aires: UNGS.

Defourny, J. y Nyssens, M. (2012). El Enfoque EMES de empresa social desde una perspectiva comparada. CIRIEC-España. Revista de Economía Pública, Social y Cooperativa, (75), 7-34.

França, F.; G. y Laville, J.L. (2004). Economia Solidária - uma abordagem internacional. Porto Alegre: UFRGS.

Gaiger, I. (2004). Emprendimientos Económicos Solidarios. En Cattani, D., La otra economía. Buenos Aires: Altamira-UNGS, 229-241.

Guerra, P. (2013). Sobre el concepto de empresa. Bases para la comprensión de formatos económicos solidarios, Revista OIDLES - Vol. 7, N 15 (disponible en: www.eumed.net/).

Guerra, P. (2014). Nuevos modelos empresariales híbridos: algunos vínculos teóricos con la de la economía social y solidaria. Revista Idelcoop, (212), 11-29. innovador, funcional a la integración de sentidos y recursos, a través de una mayor articulación, preferentemente, a partir del ámbito local.

Según Gaiger (2004), el interés legítimo por evidenciar las calidades emancipadoras de las alternativas económicas, en una perspectiva de "hermenéutica de las emergencias", no reduce la necesidad de un análisis riguroso de estas alternativas (Sousa Santos, 2011). En tanto, Razeto, en 1993 (citado por Gaiger, 2004:239), señalaba que:

"estos diferentes aspectos de la producción, distribución y consumo en la economía solidaria deben ser entendidos como la expresión teórica de comportamientos tendenciales, y no como manifestación madura y completa de lo que efectivamente existe en la realidad."

La cuestión clave sigue siendo, luego de reconocer las heterogeneidad propia de la ESS, la identificación de sentidos comunes para la construcción y fortalecimiento de movimiento(s) autónomo(s), capaz(ces) de asumir plenamente la construcción de otra economía, contrarrestando las contradicciones de un sistema-mundo que hoy más que nunca atraviesa una crisis de legitimidad y de racionalidad en sus propios términos.

Laville, J.-L. (1998). L'economia solidale. Torino: Bollati Boringhieri.

Laville, J.-L. (2008a). Economía Social en Europa: Una nueva ola de iniciativas en Europa. En Otra Economía, II(2), $1^{\circ}$ semestre, 178-180.

Laville, J.-L. (2008b). Los servicios de proximidad en Europa: en perspectiva con la economía popular. En Otra Economía, I/(3), 2 semestre, 170-174.

Laville, J.-L. y Nyssens M. (2001). The social Enterprise. Towards a theoretical socioeconomic approach. En Borzaga, C. y Defourny, J. (orgs.). The emergence of social enterprise. London and Nueva York: Routledge, 312-332.

Martí, J.P. (coord.) (2005). Cooperativas de trabajo en el Cono Sur. Matrices de surgimiento y modelos de gestión. Revista Unircoop, 3, 1º́poca, 32-56.

Oxoby, P. (2010). Una aproximación a las divergencias e implicaciones de los distintos abordajes a la Economía Social: países centrales europeos y América Latina. En Otra Economía, IV(6), $1^{\circ}$ semestre, 153-166.

Singer, P. (2009). Relaciones entre sociedad y estado en la economía solidaria. ICONOS. Revista de Ciencias Sociales, (33), 51-65. Ecuador: FLACSO.

Sousa Santos, B. de (coord.) (2011). Producir para vivir: los caminos de la producción no capitalista. México: Fondo de Cultura Económica. 